\title{
Regulation of Peroxisome Proliferator-Activated Receptors by E6-Associated Protein
}

\author{
Lakshmi Gopinathan, ${ }^{1,2}$ Daniel B. Hannon, ${ }^{2}$ Russell W. Smith III, ${ }^{2}$ Jeffrey M. Peters, ${ }^{2}$ \\ and John P. Vanden Heuvel ${ }^{2}$ \\ ${ }^{1}$ The Huck Institutes of the Life Sciences, The Pennsylvania State University, University Park, PA 16802, USA \\ ${ }^{2}$ Center for Molecular Toxicology and Carcinogenesis, Department of Veterinary \& Biomedical Sciences, \\ The Pennsylvania State University, University Park, PA 16802, USA \\ Correspondence should be addressed to John P. Vanden Heuvel, jpv2@psu.edu
}

Received 29 May 2008; Revised 25 September 2008; Accepted 5 November 2008

Recommended by Wei Xu

\begin{abstract}
Peroxisome proliferator-activated receptors (PPARs) are nuclear receptors (NRs) that regulate genes involved in lipid and glucose metabolism. PPAR activity is regulated by interactions with cofactors and of interest are cofactors with ubiquitin ligase activity. The E6-associated protein (E6-AP) is an E3 ubiquitin ligase that affects the activity of other NRs, although its effects on PPARs have not been examined. E6-AP inhibited the ligand-independent transcriptional activity of PPAR $\alpha$ and PPAR $\beta$, with marginal effects on PPAR $\gamma$, and decreased basal mRNA levels of PPAR $\alpha$ target genes. Inhibition of PPAR $\alpha$ activity required the ubiquitin ligase function of E6-AP, but occurred in a proteasome-independent manner. PPAR $\alpha$ interacted with E6-AP, and in mice treated with PPAR $\alpha$ agonist clofibrate, mRNA and protein levels of E6-AP were increased in wildtype, but not in PPAR $\alpha$ null mice, indicating a PPAR $\alpha$-dependent regulation. These studies suggest coordinate regulation of E6-AP and PPAR $\alpha$, and contribute to our understanding of the role of PPARs in cellular metabolism.
\end{abstract}

Copyright (C) 2008 Lakshmi Gopinathan et al. This is an open access article distributed under the Creative Commons Attribution License, which permits unrestricted use, distribution, and reproduction in any medium, provided the original work is properly cited.

\section{INTRODUCTION}

The peroxisome proliferator activated receptors (PPARs) are nuclear hormone receptors that regulate lipid and glucose metabolism, and are critical to the maintenance of cellular energy homeostasis. In addition, they regulate several biological processes such as inflammation, differentiation, apoptosis, and wound healing $[1,2]$. Three different subtypes of PPARs mediate these responses: $\operatorname{PPAR} \alpha, \operatorname{PPAR} \beta$, and PPAR $\gamma$. PPAR $\alpha$ is activated by fatty acids, fatty acid metabolites, and peroxisome proliferators, a diverse group of xenobiotics that includes the fibrate hypolidemic drugs, phthalate esters, and herbicides [3]. Regulation of gene expression by $\operatorname{PPAR} \alpha$ follows the classical ligand-dependent transcription factor mechanism. Upon ligand binding, PPAR $\alpha$ binds to PPAR-response elements (PPREs) in the promoter of target genes as a heterodimer with retinoid $\mathrm{X}$ receptor (RXR). The multiple protein-PPAR $\alpha$ interactions that occur in the transcription complex are important for proper target gene regulation [4]. These proteins, often called coregulators, can increase (coactivators) or repress (corepressors) transcriptional activity. Some coregulators possess enzymatic activity such as histone acetyl transferase or histone deacetylase, and modulate chromatin structure to regulate gene transcription [5]. Several proteins with ubiquitin ligase activity have been characterized in the last few years as coregulators for nuclear receptors. The recruitment of ubiquitin-proteasome components to the promoters of nuclear receptor target genes suggest an additional layer of transcriptional regulation by the ubiquitin-proteasome pathway [6-8].

This study examines regulation of PPAR $\alpha$ by E6associated protein (E6-AP), a protein linked to the Angelman syndrome and an E3 ubiquitin ligase that belongs to the HECT (homologous to the E6-AP C-terminus) family [9]. Ablation of E6-AP in mice is associated with steroid hormone resistance and reproductive defects [10]. E6-AP coactivates nuclear receptors such as the estrogen receptor (ER) and the progesterone receptor [11]. In addition, it mediates proteasomal degradation of proteins such as the nuclear receptor coactivator AIB1 [12], and tumor suppressors $\mathrm{Rb}$ 
(retinoblastoma protein), and p53 [13-15]. The studies presented here suggest a role for the ubiquitin ligase function of E6-AP in regulating PPAR $\alpha$ activity.

\section{MATERIALS AND METHODS}

\subsection{Plasmids}

The plasmids pBKRSV-E6AP, pBKRSV-E6AP-C833S, and pM-E6AP were a kind gift from Dr. Zafar Nawaz (Department of Cell Biology, Baylor College of Medicine, Houston, Tex, USA). The construction of the pVP16-PPAR $\alpha$ plasmid has been described previously [16]. The pFRluciferase (UAS luciferase) plasmid was purchased from BD Biosciences Clontech (Palo Alto, Calif, USA), while $\mathrm{pRL} / \mathrm{TK}$ and $\mathrm{pRL} / \mathrm{CMV}$ were from Promega (Madison, Wis, USA). The peroxisome proliferator response element (PPRE) reporter pACO $(-581 /-471)$ G.Luc was supplied by Dr. Jonathan Tugwood (AstraZeneca Maccelsfield, UK) and has been described previously [17]. The pcDNA3.1/V5-His$\operatorname{PPAR} \alpha$ plasmid has been described previously [16]. The pcDNA3.1/FLAG-PPAR $\beta$ and pcDNA3.1-PPAR $\gamma$ plasmids were a kind gift from Dr. Curtis Omiecinski (Department of Veterinary and Biomedical Sciences, The Pennsylvania State University, Pa, USA).

\subsection{Transfections and reporter assays}

FaO cells (maintained in DMEM/Nutrient F-12 Ham with $8 \%$ serum and 100 units each of penicillin and streptomycin) were transfected using Lipofectamine RNAiMAX reagent (Invitrogen, Carlsbad, Calif, USA), following manufacturer's instructions. Lipofectamine (Invitrogen) was used to transfect 293 T cells (maintained in HG-DMEM with $8 \%$ serum and 100 units each of penicillin and streptomycin) according to the manufacturer's instructions. For reporter assays examining transient PPRE activity, all transfections included pRL/CMV (Promega) to control for transfection efficiency and ACO-luciferase. When indicated, following transfection, cells were treated with $0.1 \%$ DMSO or $5 \mu \mathrm{M}$ MG132 for 6 hours. For reporter assays examining transient Gal4 response element activity, all transfections included pRL/CMV to control for transfection efficiency and pFR-Luciferase. In Gal4 response element assays, cells were treated for 6 hours with $0.1 \%$ DMSO or $50 \mu \mathrm{M}$ Wy-14,643 before lysis. Cells were lysed and renilla and firefly luciferase activities were examined using the Dual Luciferase Assay kit (Promega). Luciferase activity was corrected for transfection efficiency (pRLTK/pRLCMV) and extraction yield (via total protein assay).

\subsection{Real-time PCR}

Total RNA was isolated using Tri Reagent (Sigma, St. Louis, Mo, USA) according to the manufacturer's protocol. The total RNA was reverse transcribed using the ABI High Capacity cDNA Archive Kit (Applied Biosystems, Foster City, Calif, USA). Standard curves were made using serial dilutions from pooled cDNA samples. Real Time PCR was performed using the SYBR Green PCR Mater Mix (Applied Biosystems) according to the manufacturer's protocol and amplified on the ABI Prism 7300 Sequence Detection system. Messenger RNA levels of all genes were normalized to $\beta$-actin mRNA. Primer sequences $\left(5^{\prime}-3^{\prime}\right)$ are E6-AP forward: gaaatgaggcctgcacgaat, E6-AP reverse: gaagaaaagttggacaggaagca, $\beta$-actin forward: ggctctatcctggcctcactg, $\beta$-actin reverse: cttgctgatccacatctgctg. Primers for Acyl CoA Oxidase (ACO) Cytochrome P450 IV A10 (CYP4A10), Angiopoietin-like protein 4 (Angplt4), have been described previously [16]. Sequences $\left(5^{\prime}-3^{\prime}\right)$ for other genes measured are fatty acid binding protein 1 (FABP1) forward: ttctccggcaagtaccaagtg, FABP1 reverse: tcatgaagggctcaaagttctctt, Enoyl CoA Hydratase forward: cccgcaggatctttaacaagc, Enoyl CoA Hydratase reverse: cactgtccatgttgggcaag.

\subsection{Western blotting}

Mouse livers were homogenized in lysis buffer containing $50 \mathrm{mM}$ Tris ( $\mathrm{pH} 8$ ), $120 \mathrm{mM} \mathrm{NaCl}, 0.5 \%$ Nonidet P-40, and 1 : 100 dilution of protease-inhibitor cocktail (Sigma) after which particulates were removed by centrifugation. Liver lysates were subjected to SDS/PAGE. Proteins were transferred to Immobilon-PVDF membrane (Millipore), followed by western using anti-E6AP antibody (H-182, Santa Cruz Biotechnology). Band intensities were quantitated using Optiquant Acquisition and Analysis Software.

\subsection{Mice}

8-week old-male wild-type, and PPAR $\alpha$-null mice [18] were housed in a light (12 hours light/12 hours dark) and temperature $\left(25^{\circ} \mathrm{C}\right)$ controlled environment in microisolator cages. Mice were gavaged daily with either vehicle control (corn oil) or $500 \mathrm{mg}$ clofibrate/kg body weight for 14 days. Mice were euthanized, livers weighed and homogenized, RNA or protein isolated for analysis as described above.

\section{RESULTS}

\subsection{E6-AP inhibits the transcriptional activity of PPAR $\alpha$, PPAR $\beta$, and PPAR $\gamma$}

The transcriptional activity of $\operatorname{PPAR} \alpha, \operatorname{PPAR} \beta / \delta$, and $\operatorname{PPAR} \gamma$ isotypes was examined in the presence of E6-AP, by measuring the activity of a reporter gene under the control of a natural PPRE. As seen in Figure 1, transfecting increasing amounts of E6-AP inhibited PPAR transactivation in a dosedependent manner for all three PPAR isotypes. A $40 \%$ decrease in transactivation was observed for $\operatorname{PPAR} \alpha$ and $\operatorname{PPAR} \beta$, with a statistically significant decrease observed first at a ratio of $1.5: 1$ for E6-AP : PPAR $\alpha$, and 2 : 1 for E6AP : PPAR $\beta$. A $30 \%$ decrease in transactivation was seen with PPAR $\gamma$, with a statistically significant decrease observed first at a ratio of $3: 1$ for E6-AP : PPAR $\gamma$. No changes were observed in ligand-induced activity of the receptors in the presence of E6-AP (data not shown). 


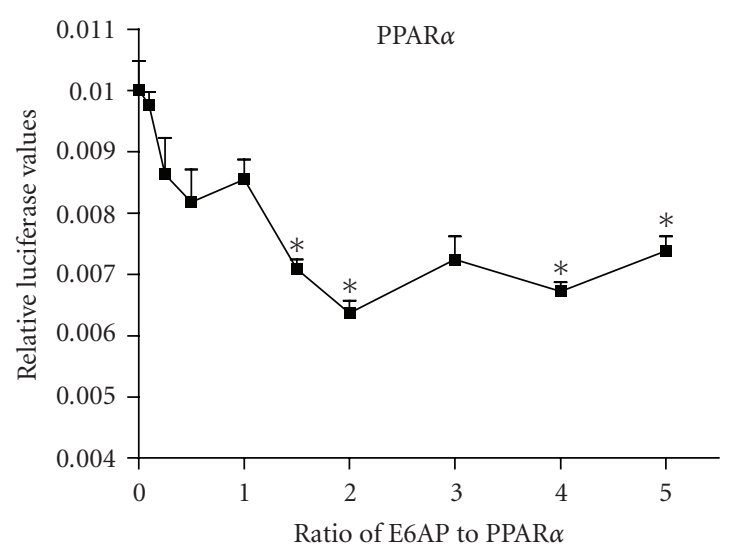

(a)

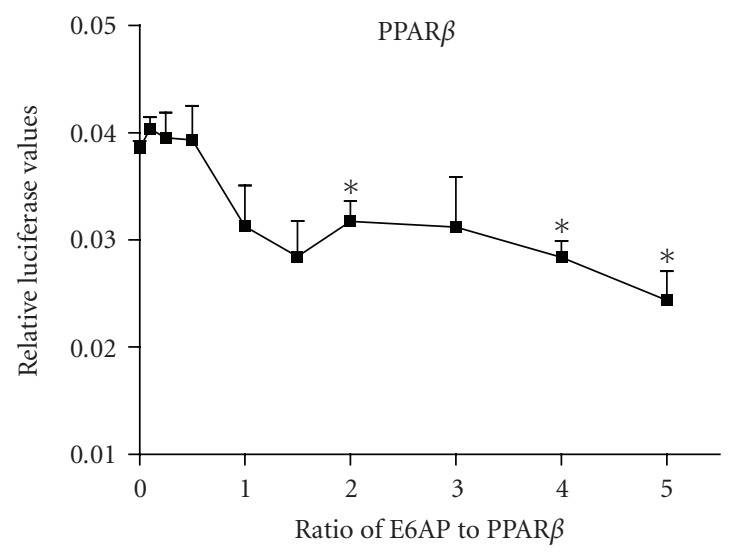

(b)

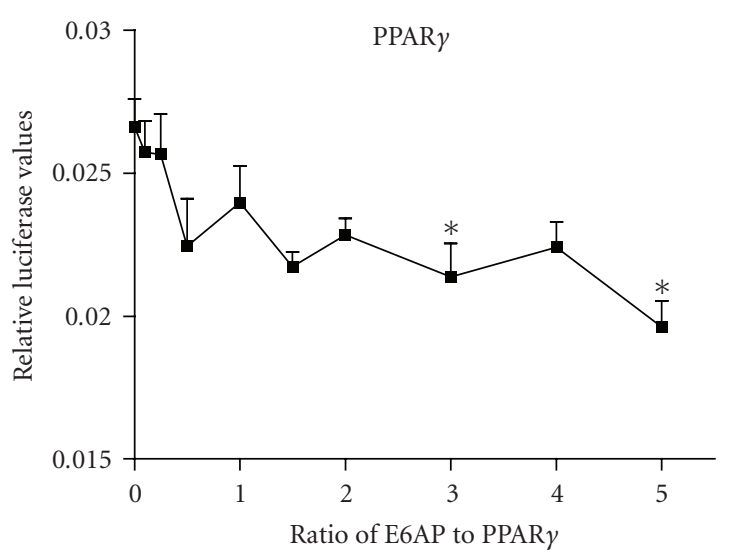

(c)

FIgURE 1: E6-AP inhibits the transcriptional activity of PPAR $\alpha$, $\operatorname{PPAR} \beta$, and $\operatorname{PPAR} \gamma$. 293T cells were transfected with plasmids expressing $4 \mathrm{X}$-ACO-Luciferase, $\mathrm{pRLCMV}, \operatorname{PPAR} \alpha, \operatorname{PPAR} \beta$ or PPAR $\gamma$, and E6-AP. Cells were lysed and luciferase activity was corrected for transfection efficiency and protein. Asterisks indicate a significant difference in luciferase values when compared to the 0 ratio group. ( ${ }^{*} P<.05$ with statistical analysis using ANOVA). The graphs are representative of 3 independent experiments.

\subsection{E6-AP overexpression affects PPAR $\alpha$ target genes}

To further examine the effect of E6-AP on the transcriptional activity of $\operatorname{PPAR} \alpha, \mathrm{E} 6-\mathrm{AP}$ was expressed in $\mathrm{FaO}$ cells by transient transfection, followed by treatment with PPAR $\alpha$ ligand Wy-14,643. The effect of E6-AP overexpression on mRNA levels of endogenous PPAR $\alpha$ target genes was measured. The genes examined (angiopoietin-like protein 4 or Angplt4, fatty acid binding protein 1 or FABP1, acyl CoA oxidase or ACO and enoyl CoA hydratase) were chosen based on their role in PPAR $\alpha$-mediated lipid metabolism, or were previously identified in gene expression microarrays in $\mathrm{FaO}$ cells [19]. As seen in Figure 2, E6-AP expression resulted in statistically significant changes in mRNA levels Angplt4 (24\% decrease) and FABP1 (28\% decrease), in the absence of ligand. As previously seen with PPRE-driven reporter assays (Figure 1), no changes were seen in ligandinduced mRNA levels of PPAR $\alpha$ target genes with E6AP expression.

\subsection{E6-AP interacts with PPAR $\alpha$}

To examine if the effect of E6-AP on the transcriptional activity of PPAR $\alpha$ was due to a direct interaction between the two proteins, mammalian-two-hybrid assays were performed using plasmids expressing PPAR $\alpha$ fused to the pVP16 activation domain and E6-AP in the pM vector. The Gal4 response element reporter ( $\mathrm{pFR}$-luciferase) was used to assess the interaction between E6-AP and PPAR $\alpha$. As seen in Figure 3, induction with PPAR $\alpha$ agonist $\mathrm{Wy}-14,643$ was seen only when E6-AP was coexpressed with $\operatorname{PPAR} \alpha$, indicating an interaction between the two proteins.

\subsection{The E3 ubiquitin ligase function of E6-AP is required for inhibition of PPAR $\alpha$ transcriptional activity}

In order to determine if the effect of E6-AP on PPAR $\alpha$ activity was mediated by the E3 ubiquitin ligase function of E6AP, E6-AP C833S, a mutant defective in ubiquitin ligase function was used. Unlike the changes in reporter activity seen with wildtype (WT) E6-AP (Figure 1), transfecting increasing amounts of E6-AP-C833S did not result in any changes in activity (Figure 4(a)), indicating that the ubiquitin ligase function of E6-AP is required for regulating the transcriptional activity of PPAR $\alpha$. These differences were not due to different transfection efficiencies, since both E6AP WT and E6-AP-C833S expressed equally well in these cells (data not shown). To further assess if E6-AP-mediated inhibition of PPAR $\alpha$ transactivation was via proteasomal degradation, PPRE-dependent reporter assay was performed in the presence of proteasome inhibitor MG132. Transfecting increasing amounts of E6-AP resulted in decreased reporter activity in the presence and absence of MG132 (Figure 4(b)), indicating that E6-AP-mediated inhibition of PPAR $\alpha$ transactivation occurs via a proteasome-independent mechanism. 


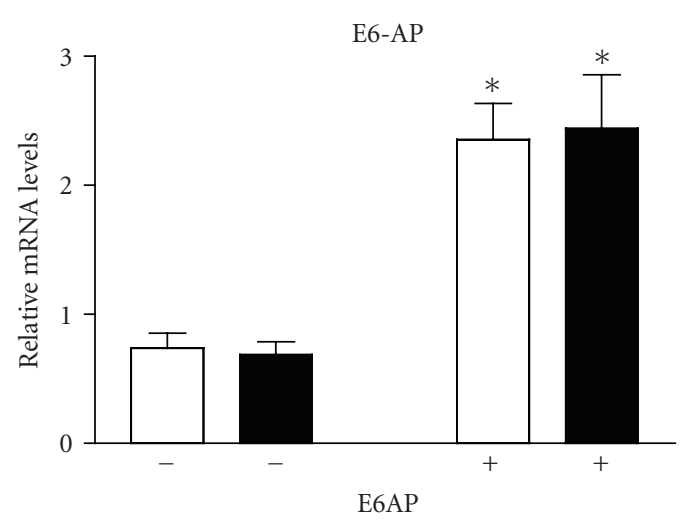

DMSO
Wy-14,643

(a)

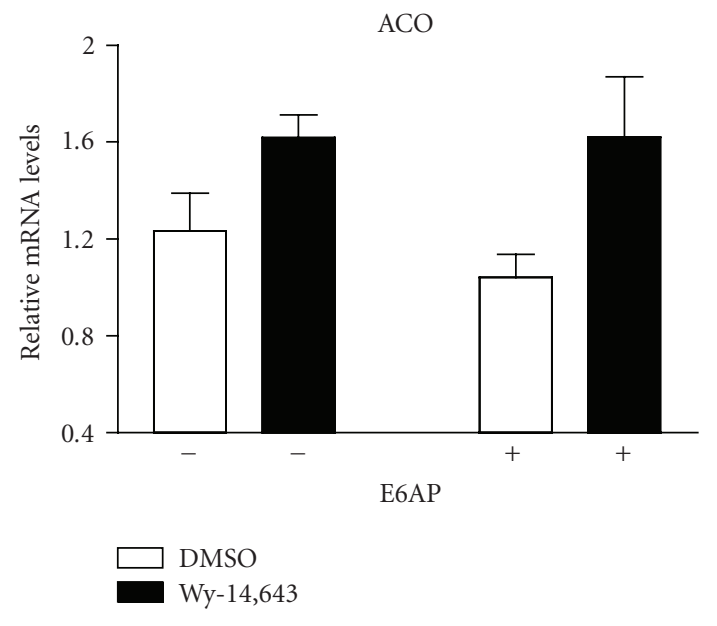

(b)

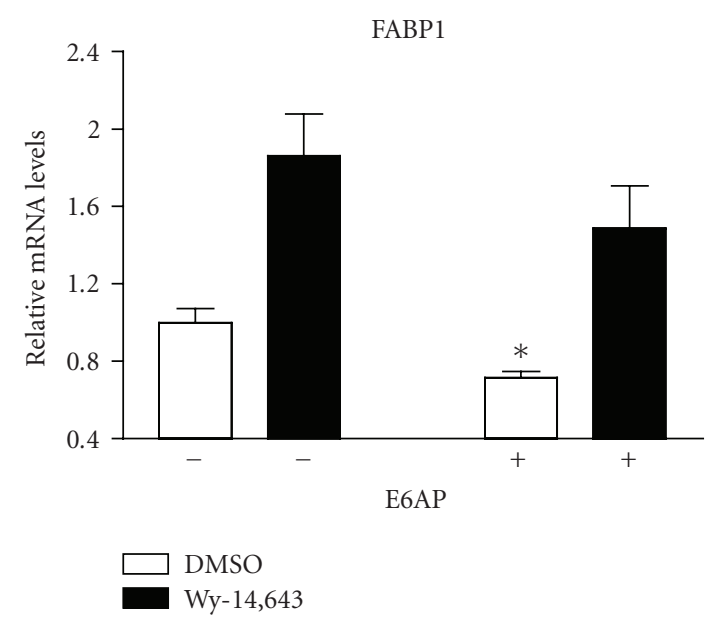

(d)

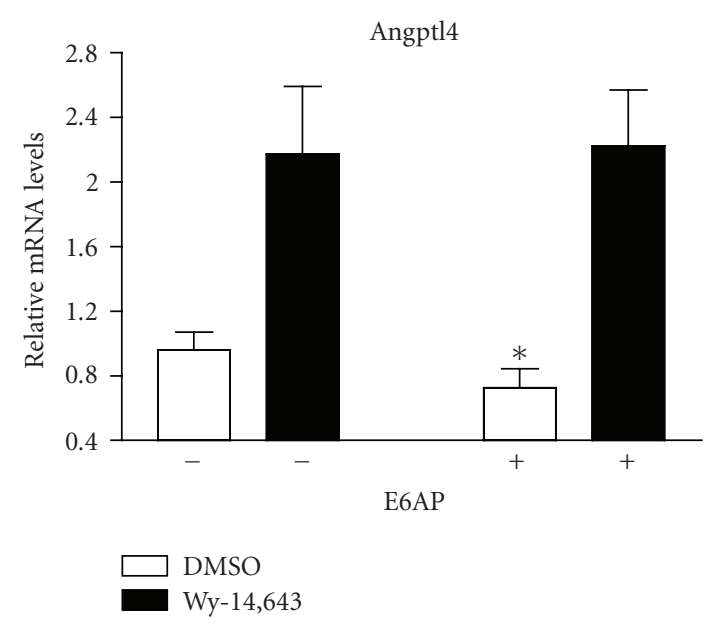

(c)

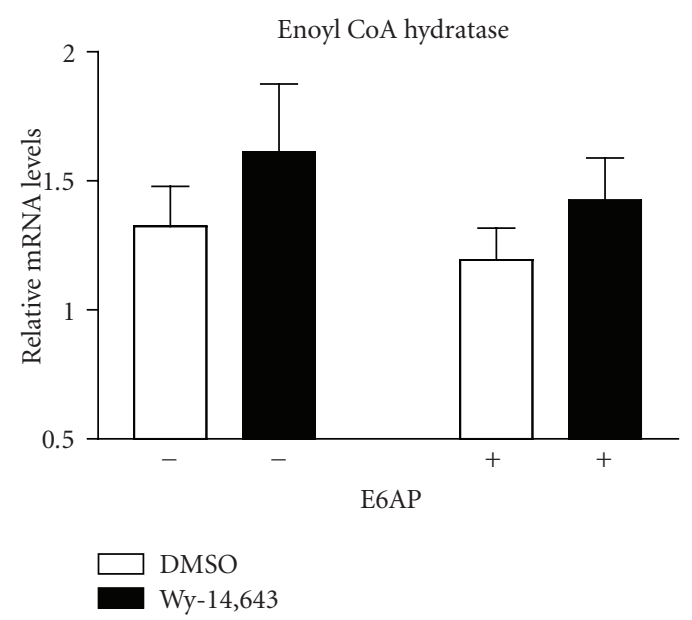

(e)

FIGURE 2: E6-AP expression results in decreased mRNA levels of PPAR $\alpha$ target genes. FaO cells were transfected with empty vector or plasmid expressing E6-AP, followed by treatment with $0.1 \%$ DMSO or $50 \mu \mathrm{M}$ Wy-14,643 for 6 hours. Total RNA was isolated from the cells and realtime PCR was performed on reverse transcribed RNA. Asterisks indicate a significant difference when compared to the corresponding control group. ( ${ }^{*} P<.05$ with statistical analysis using ANOVA). The graphs represent mean values obtained from 2 independent experiments. 


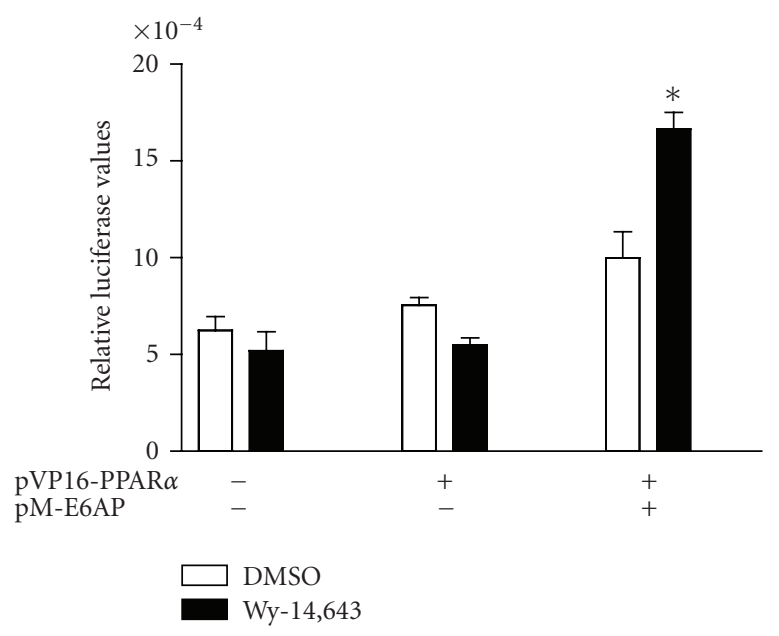

FIgURE 3: E6-AP interacts with PPAR $\alpha$. 293T cells were transfected with plasmids expressing pFR-Luciferase, pRLCMV, pVP16-PPAR $\alpha$, pM-E6-AP. Cells were lysed and luciferase activity was corrected for transfection efficiency and protein. Asterisks indicate a significant difference in Wy-14,643 induction when compared to the corresponding DMSO group. $\left({ }^{*} P<.05\right.$ with statistical analysis using ANOVA). The graph is representative of 2 independent experiments.

\subsection{E6-AP is regulated in vivo in a PPAR $\alpha$-dependent manner}

Since NR-mediated transcriptional regulation of E3 ligases has been demonstrated in a few studies [20-22], regulation of E6-AP in response to PPAR $\alpha$ ligand was examined in vivo. Wild type and PPAR $\alpha$ null mice were maintained on a clofibrate or control diet for two weeks, following which their livers were analyzed for mRNA and protein levels of E6-AP. As expected, mRNA levels of known PPAR $\alpha$ target genes (acyl CoA oxidase or ACO and cytochrome P450 IV A10 or CYP4A10) were induced in response to clofibrate and this response was defective in PPAR $\alpha$ null mice (Figure 5(a)). E6-AP mRNA (Figure 5(a)) and protein (Figure 5(b)) levels were significantly increased in wildtype mice in response to clofibrate, but not in $\operatorname{PPAR} \alpha$ null mice, indicating a $\operatorname{PPAR} \alpha$ dependent regulation.

\section{DISCUSSION}

The regulation of PPARs by the ubiquitination has been the subject of limited investigation. However, recent studies suggest ligand-mediated regulation of PPARs via the ubiquitin-proteasome system, although no ubiquitin ligase has been identified. PPAR $\alpha$ and $\operatorname{PPAR} \beta$ ligands affect receptor ubiquitination and protein levels [23-26]. Ligand binding induces transcriptional activation of PPAR $\gamma$ that is followed by degradation [27]. This study identifies the E3 ubiquitin ligase E6-AP, as regulator of PPAR activity. The transcriptional activity of all three PPAR isotypes was inhibited by E6-AP. No changes were observed in ligandinduced transcriptional activity in the presence of E6-AP. $\operatorname{PPAR} \alpha$ and E6-AP interacted in mammalian two hybrid

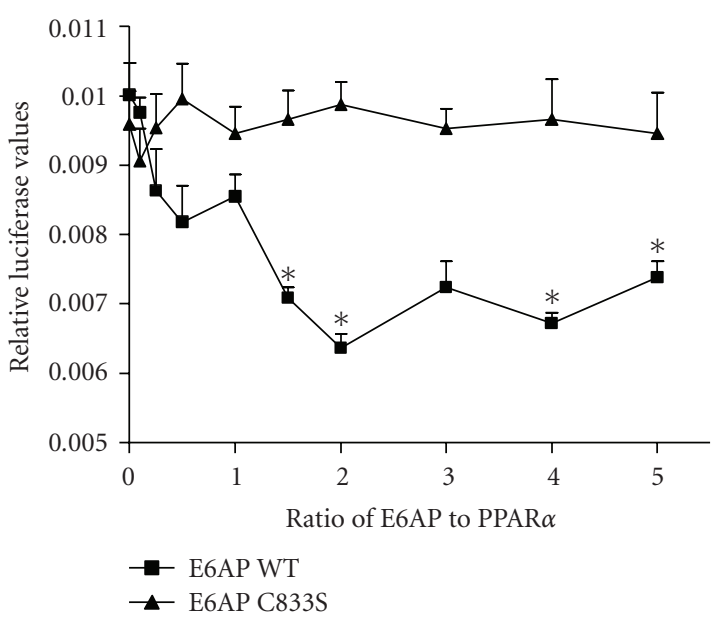

(a)

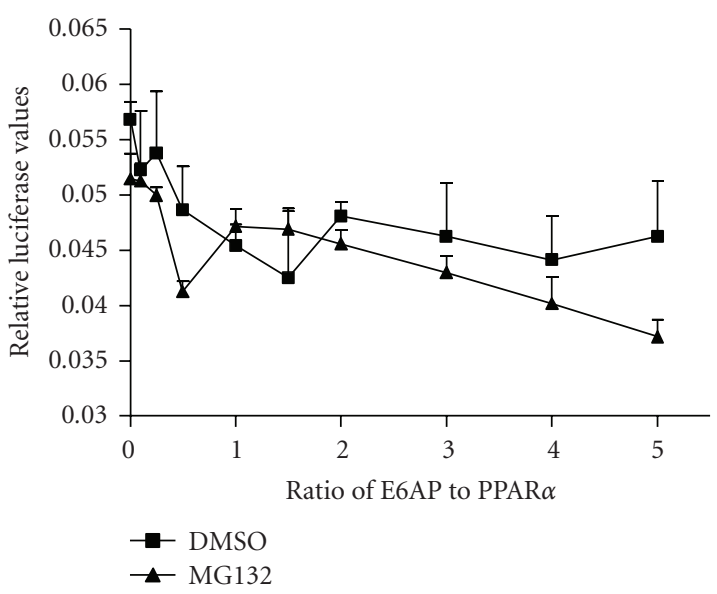

(b)

FIgURE 4: E3 ubiquitin ligase activity of E6-AP is required for regulating PPAR $\alpha$ transactivation. (a) $293 \mathrm{~T}$ cells were transfected with plasmids expressing $4 \mathrm{X}$-ACO-Luciferase, pRLCMV, PPAR $\alpha$, E6-AP, or E6-AP-C833S that is defective in ubiquitin ligase function. (b) Cells were treated with $0.1 \%$ DMSO or $5 \mu \mathrm{M}$ MG132 for 6 hours. Cells were lysed and luciferase activity was corrected for transfection efficiency and protein. Asterisks indicate a significant difference when compared to the corresponding 0 ratio group. $\left({ }^{*} P<.05\right.$ with statistical analysis using ANOVA). The graph is representative of 3 independent experiments.

assays, and by using an E6-AP mutant defective in ubiquitin ligase activity, we demonstrate that inhibition of PPAR $\alpha$ activity required the E3 ubiquitin ligase function of E6-AP. Interestingly, the presence of proteasome inhibitor MG132 had no effect on inhibition of $\operatorname{PPAR} \alpha$ transactivation, suggesting that the proteasomal degradation is not required for E6-AP-mediated regulation of receptor transcriptional activity. This finding points to nonproteolytic functions of ubiquitination in modulating PPAR $\alpha$ activity. The multifaceted roles of ubiquitin in regulating protein localization, recruiting coregulators, and modifying chromatin structure are now well-recognized $[7,8,28]$. It would be of interest to 

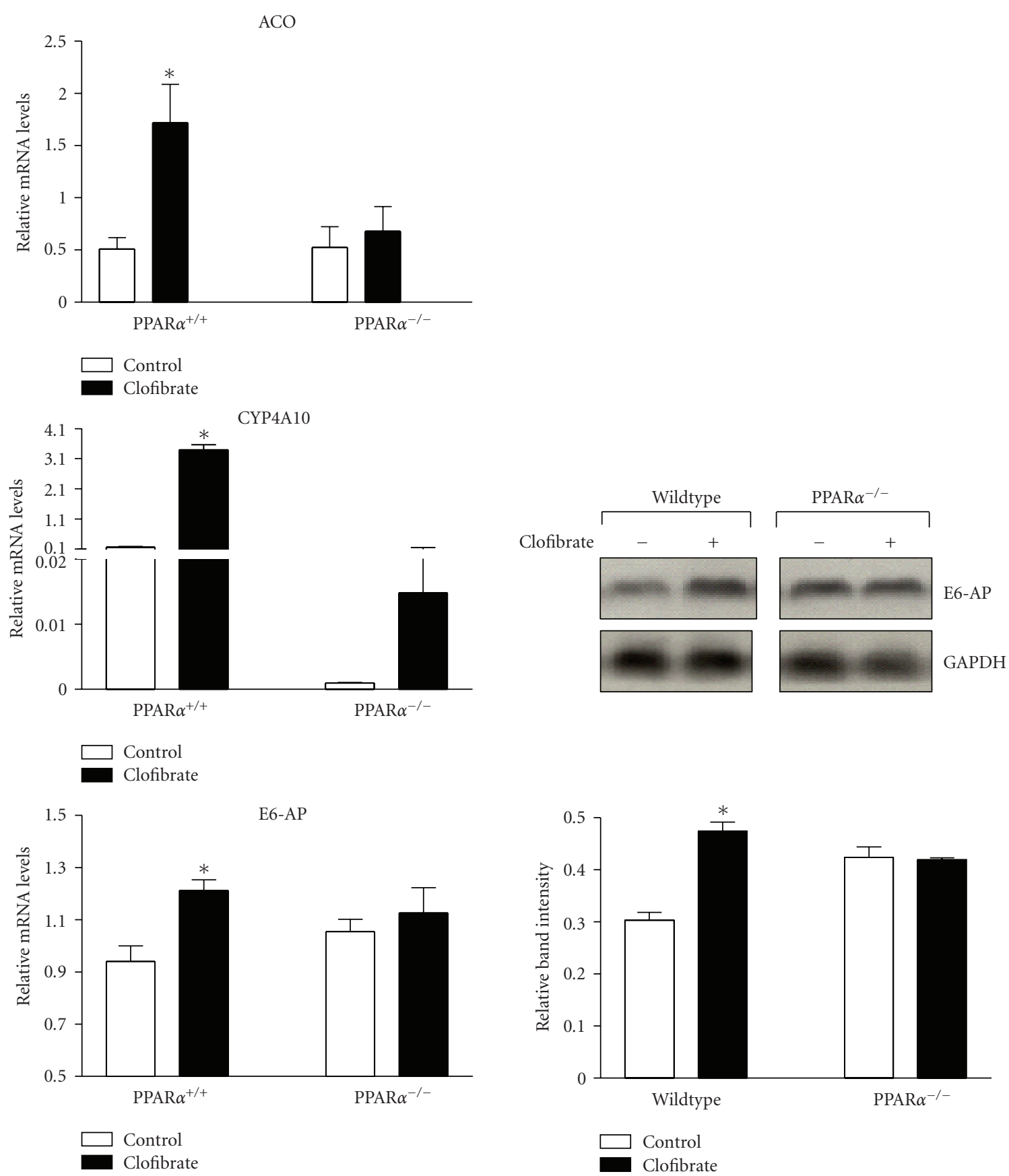

(a)

(b)

FIGURE 5: E6-AP is induced by clofibrate in a PPAR $\alpha$-dependent manner. Wildtype and PPAR $\alpha$ null mice were treated with control vehicle or clofibrate for 2 weeks. Groups of five mice were used for each treatment. (a) Total RNA was isolated from liver and mRNA levels were measured using real-time PCR. (b) Protein isolated from liver was analyzed for E6AP expression by western blot. The graph (lower panel) depicts mean $(n=5)$ band intensity. Asterisks indicate a significant increase in clofibrate induction when compared to the PPAR $\alpha$ null group. ( ${ }^{*}<.05$ with statistical analysis using ANOVA).

examine these possibilities in regulation of PPAR $\alpha$ function by E6-AP.

The inhibition of PPAR $\alpha$ transcriptional activity by E6$\mathrm{AP}$ is in contrast to previous findings with the progesterone receptor, where E6-AP coactivated receptor function, and the ubiquitin ligase activity was dispensable for its coactivating ability [11]. These observations suggest different mechanisms of E6-AP-mediated regulation of nuclear receptors. E6-AP is recruited to the ER-responsive pS2 promoter and is preferentially associated with E2-liganded ER $\alpha$ [29]. It would be of interest to determine if E6-AP is recruited to promoters of PPAR $\alpha$ target genes, as a mechanism of 
transcriptional regulation. Evidence also exists for NRmediated transcriptional regulation of E3 ligases. Estrogen activation of ER $\alpha$ induces the expression of two ubiquitin ligases, MDM2 and Siah2 [20-22]. MDM2 is also regulated by the thyroid hormone receptor [30] orphan receptor TR3 [31], and constitutive androstane receptor (CAR) [32]. The breast cancer associated gene (BCA2) was identified as an E3 ubiquitin ligase and BCA2 expression correlates with positive ER status in breast tumors, suggesting that BCA2 and ER might be coregulated [21]. Our study shows that E6-AP mRNA and protein levels are increased in mice in response to $\operatorname{PPAR} \alpha$ ligand clofibrate in wildtype but not $\operatorname{PPAR} \alpha$ null mice, indicating a coordinate mode of regulation between PPAR $\alpha$ and E6-AP. In contrast to the ligand-independent decrease in PPAR $\alpha$ transcriptional activity mediated by E6AP in $\mathrm{FaO}$ cells, ligand treatment resulted in an increase in E6AP expression in mice that was PPAR $\alpha$-dependent. These results allude to the existence of a feedback loop between $\operatorname{PPAR} \alpha$ and E6-AP wherein PPAR $\alpha$ increases the expression of a negative regulator for control of its transcriptional activity.

Studies in our laboratory have identified MDM2 as another ubiquitin ligase for PPAR $\alpha$ (unpublished results). MDM2 regulated the transcriptional activity of PPAR $\alpha$ by being recruited to the promoters of PPAR $\alpha$ target genes in response to ligand, and it interacted with the A/B domain of PPAR $\alpha$. The various biological processes regulated by PPARs are crucial in control of disorders such as diabetes, inflammation, and cardiovascular ailments, and ubiquitin ligases such as E6-AP and MDM2 may present useful targets for pharmacological intervention and improved PPAR-based therapeutics.

In addition to contributing to understanding PPAR regulation by ubiquitination, other interesting connections can be made about the significance of the E6-AP-PPAR $\alpha$ interaction. E6-AP mediates ubiquitination and degradation of the Hepatitis $\mathrm{C}$ virus (HCV) core protein, which plays a crucial role in HCV-related liver disease [33]. HCV infections are associated with reduced hepatic PPAR $\alpha$ expression [3437], and PPAR $\alpha$ is implicated in HCV core protein-mediated hepatic steatosis and dysregulated lipid metabolism [37]. The regulation of PPAR $\alpha$ by E6-AP may provide a basis for $\mathrm{HCV}$-induced progression of liver disease, and is worthy of investigation.

\section{CONCLUSIONS}

This study identifies E6-AP, an E3 ubiquitin ligase, as a PPAR $\alpha$-interacting protein that inhibited ligandindependent PPAR $\alpha$ transactivation and decreased the basal mRNA levels of PPAR $\alpha$ target genes. The E3 ubiquitin ligase function of E6AP was required for inhibition of PPAR $\alpha$ transcriptional activity, and this inhibition occurred in a proteasome-independent manner. E6-AP was induced in vivo in response to $\operatorname{PPAR} \alpha$ ligand, and was regulated in a PPAR $\alpha$-dependent manner. A better understanding of the role of E6-AP and other ubiquitin ligases in the regulation of PPARs could help improve treatment strategies against metabolic diseases.

\section{ACKNOWLEDGMENTS}

This work was funded by NIH ES07799 awarded to J. P. Vanden Heuvel. The authors thank Cherie Anderson for help with mouse experiments.

\section{REFERENCES}

[1] J. N. Feige, L. Gelman, L. Michalik, B. Desvergne, and W. Wahli, "From molecular action to physiological outputs: peroxisome proliferator-activated receptors are nuclear receptors at the crossroads of key cellular functions," Progress in Lipid Research, vol. 45, no. 2, pp. 120-159, 2006.

[2] B. Desvergne, L. Michalik, and W. Wahli, "Be fit or be sick: peroxisome proliferator-activated receptors are down the road," Molecular Endocrinology, vol. 18, no. 6, pp. 1321-1332, 2004.

[3] P. Escher and W. Wahli, "Peroxisome proliferator-activated receptors: insight into multiple cellular functions," Mutation Research/Fundamental and Molecular Mechanisms of Mutagenesis, vol. 448, no. 2, pp. 121-138, 2000.

[4] S. Yu and J. K. Reddy, "Transcription coactivators for peroxisome proliferator-activated receptors," Biochimica et Biophysica Acta, vol. 1771, no. 8, pp. 936-951, 2007.

[5] C. K. Glass and M. G. Rosenfeld, "The coregulator exchange in transcriptional functions of nuclear receptors," Genes \& Development, vol. 14, no. 2, pp. 121-141, 2000.

[6] A. Ismail and Z. Nawaz, "Nuclear hormone receptor degradation and gene transcription: an update," IUBMB Life, vol. 57, no. 7, pp. 483-490, 2005.

[7] H. K. Kinyamu, J. Chen, and T. K. Archer, "Linking the ubiquitin-proteasome pathway to chromatin remodeling/modification by nuclear receptors," Journal of Molecular Endocrinology, vol. 34, no. 2, pp. 281-297, 2005.

[8] C. Rochette-Egly, "Dynamic combinatorial networks in nuclear receptor-mediated transcription," The Journal of Biological Chemistry, vol. 280, no. 38, pp. 32565-32568, 2005.

[9] T. Matsuura, J. S. Sutcliffe, P. Fang, et al., "De novo truncating mutations in E6-Ap ubiquitin-protein ligase gene (UBE3A) in Angelman syndrome," Nature Genetics, vol. 15, no. 1, pp. 7477, 1997.

[10] C. L. Smith, D. G. DeVera, D. J. Lamb, et al., "Genetic ablation of the steroid receptor coactivator-ubiquitin ligase, E6-AP, results in tissue-selective steroid hormone resistance and defects in reproduction," Molecular and Cellular Biology, vol. 22, no. 2, pp. 525-535, 2002.

[11] Z. Nawaz, D. M. Lonard, C. L. Smith, et al., "The Angelman syndrome-associated protein, E6-AP, is a coactivator for the nuclear hormone receptor superfamily," Molecular and Cellular Biology, vol. 19, no. 2, pp. 1182-1189, 1999.

[12] A. Mani, A. S. Oh, E. T. Bowden, et al., "E6AP mediates regulated proteasomal degradation of the nuclear receptor coactivator amplified in breast cancer 1 in immortalized cells," Cancer Research, vol. 66, no. 17, pp. 8680-8686, 2006.

[13] T. Munakata, Y. Liang, S. Kim, et al., "Hepatitis C virus induces E6AP-dependent degradation of the retinoblastoma protein," PLoS Pathogens, vol. 3, no. 9, pp. 1335-1347, 2007.

[14] M. Scheffner, J. M. Huibregtse, R. D. Vierstra, and P. M. Howley, "The HPV-16 E6 and E6-AP complex functions as a ubiquitin-protein ligase in the ubiquitination of p53," Cell, vol. 75, no. 3, pp. 495-505, 1993. 
[15] Y. Liu and J. D. Baleja, "Structure and function of the papillomavirus E6 protein and its interacting proteins," Frontiers in Bioscience, vol. 13, no. 1, pp. 121-134, 2008.

[16] E. S. Tien, J. W. Davis, and J. P. Vanden Heuvel, "Identification of the CREB-binding protein/p300-interacting protein CITED2 as a peroxisome proliferator-activated receptor $\alpha$ coregulator," The Journal of Biological Chemistry, vol. 279, no. 23, pp. 24053-24063, 2004.

[17] J. P. Gray, J. W. Davis II, L. Gopinathan, T. L. Leas, C. A. Nugent, and J. P. Vanden Heuvel, "The ribosomal protein rpL11 associates with and inhibits the transcriptional activity of peroxisome proliferator-activated receptor- $\alpha$," Toxicological Sciences, vol. 89, no. 2, pp. 535-546, 2006.

[18] S. S.-T. Lee, T. Pineau, J. Drago, et al., "Targeted disruption of the $\alpha$ isoform of the peroxisome proliferator-activated receptor gene in mice results in abolishment of the pleiotropic effects of peroxisome proliferators," Molecular and Cellular Biology, vol. 15, no. 6, pp. 3012-3022, 1995.

[19] E. S. Tien, J. P. Gray, J. M. Peters, and J. P. Vanden Heuvel, "Comprehensive gene expression analysis of peroxisome proliferator-treated immortalized hepatocytes: identification of peroxisome proliferator-activated receptor $\alpha$-dependent growth regulatory genes," Cancer Research, vol. 63, no. 18, pp. 5767-5780, 2003.

[20] H. K. Kinyamu and T. K. Archer, "Estrogen receptordependent proteasomal degradation of the glucocorticoid receptor is coupled to an increase in Mdm2 protein expression," Molecular and Cellular Biology, vol. 23, no. 16, pp. 58675881, 2003.

[21] A. M. Burger, Y. Gao, Y. Amemiya, et al., "A novel RING-type ubiquitin ligase breast cancer-associated gene 2 correlates with outcome in invasive breast cancer," Cancer Research, vol. 65, no. 22, pp. 10401-10412, 2005.

[22] J. Zhang, M. G. Guenther, R. W. Carthew, and M. A. Lazar, "Proteasomal regulation of nuclear receptor corepressormediated repression," Genes \& Development, vol. 12, no. 12, pp. 1775-1780, 1998.

[23] C. Blanquart, O. Barbier, J.-C. Fruchart, B. Staels, and C. Glineur, "Peroxisome proliferator-activated receptor $\alpha$ $(\operatorname{PPAR} \alpha)$ turnover by the ubiquitin-proteasome system controls the ligand-induced expression level of its target genes," The Journal of Biological Chemistry, vol. 277, no. 40, pp. 37254-37259, 2002.

[24] C. Blanquart, R. Mansouri, J.-C. Fruchart, B. Staels, and C. Glineur, "Different ways to regulate the PPAR $\alpha$ stability," Biochemical and Biophysical Research Communications, vol. 319, no. 2, pp. 663-670, 2004.

[25] D. Genini and C. V. Catapano, "Block of nuclear receptor ubiquitination: a mechanism of ligand-dependent control of peroxisome proliferator-activated receptor $\delta$ activity," The Journal of Biological Chemistry, vol. 282, no. 16, pp. 11776-11785, 2007.

[26] M. Rieck, L. Wedeken, S. Müller-Brüsselbach, W. Meissner, and R. Müller, "Expression level and agonist-binding affect the turnover, ubiquitination and complex formation of peroxisome proliferator activated receptor $\beta$," FEBS Journal, vol. 274, no. 19, pp. 5068-5076, 2007.

[27] S. Hauser, G. Adelmant, P. Sarraf, H. M. Wright, E. Mueller, and B. M. Spiegelman, "Degradation of the peroxisome proliferator-activated receptor $\gamma$ is linked to ligand-dependent activation," The Journal of Biological Chemistry, vol. 275, no. 24, pp. 18527-18533, 2000.
[28] R. C. Conaway, C. S. Brower, and J. W. Conaway, "Emerging roles of ubiquitin in transcription regulation," Science, vol. 296, no. 5571, pp. 1254-1258, 2002.

[29] G. Reid, M. R. Hübner, R. Métivier, et al., "Cyclic, proteasomemediated turnover of unliganded and liganded ER $\alpha$ on responsive promoters is an integral feature of estrogen signaling," Molecular Cell, vol. 11, no. 3, pp. 695-707, 2003.

[30] J.-S. Qi, Y. Yuan, V. Desai-Yajnik, and H. H. Samuels, "Regulation of the mdm2 oncogene by thyroid hormone receptor," Molecular and Cellular Biology, vol. 19, no. 1, pp. 864-872, 1999.

[31] B.-X. Zhao, H.-Z. Chen, N.-Z. Lei, et al., "p53 mediates the negative regulation of MDM2 by orphan receptor TR3," The EMBO Journal, vol. 25, no. 24, pp. 5703-5715, 2006.

[32] W. Huang, J. Zhang, M. Washington, et al., "Xenobiotic stress induces hepatomegaly and liver tumors via the nuclear receptor constitutive androstane receptor," Molecular Endocrinology, vol. 19, no. 6, pp. 1646-1653, 2005.

[33] M. Shirakura, K. Murakami, T. Ichimura, et al., "E6AP ubiquitin ligase mediates ubiquitylation and degradation of hepatitis C virus core protein," Journal of Virology, vol. 81, no. 3, pp. 1174-1185, 2007.

[34] S. Dharancy, M. Malapel, G. Perlemuter, et al., "Impaired expression of the peroxisome proliferator-activated receptor alpha during hepatitis C virus infection," Gastroenterology, vol. 128, no. 2, pp. 334-342, 2005.

[35] Y. Cheng, S. Dharancy, M. Malapel, and P. Desreumaux, "Hepatitis $\mathrm{C}$ virus infection down-regulates the expression of peroxisome proliferator-activated receptor $\alpha$ and carnitine palmitoyl acyl-CoA transferase 1A," World Journal of Gastroenterology, vol. 11, no. 48, pp. 7591-7596, 2005.

[36] A. De Gottardi, V. Pazienza, P. Pugnale, et al., "Peroxisome proliferator-activated receptor- $\alpha$ and $-\gamma$ mRNA levels are reduced in chronic hepatitis $\mathrm{C}$ with steatosis and genotype 3 infection," Alimentary Pharmacology \& Therapeutics, vol. 23, no. 1, pp. 107-114, 2006.

[37] B. Rakic, S. M. Sagan, M. Noestheden, et al., "Peroxisome proliferator-activated receptor $\alpha$ antagonism inhibits hepatitis C virus replication," Chemistry \& Biology, vol. 13, no. 1, pp. 23-30, 2006. 


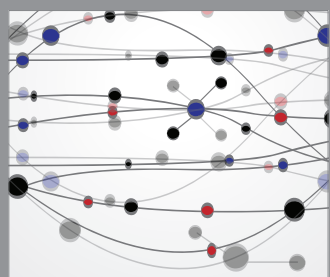

The Scientific World Journal
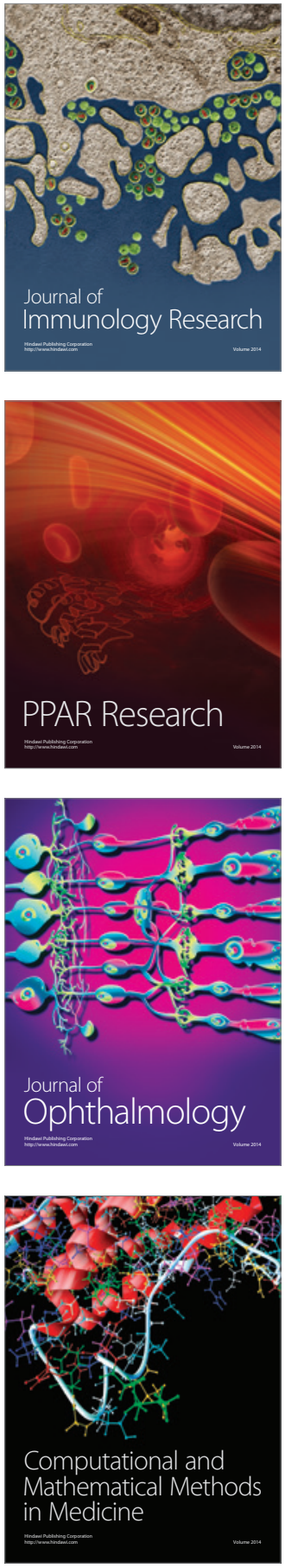

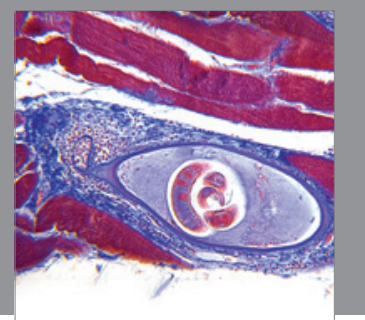

Gastroenterology

Research and Practice
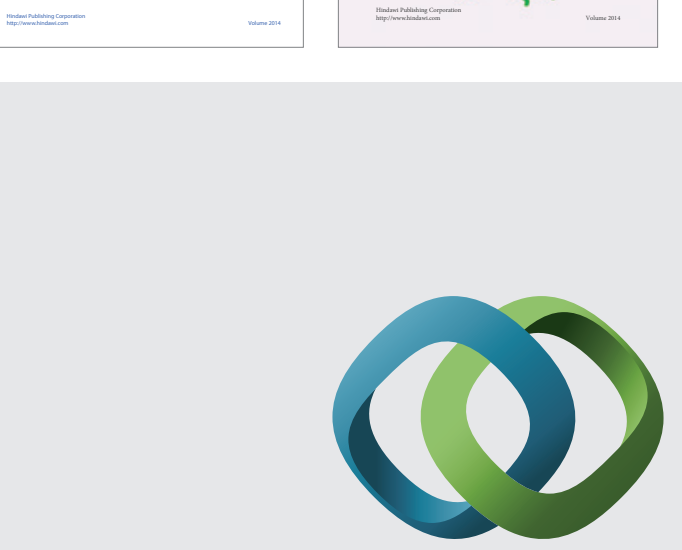

\section{Hindawi}

Submit your manuscripts at

http://www.hindawi.com
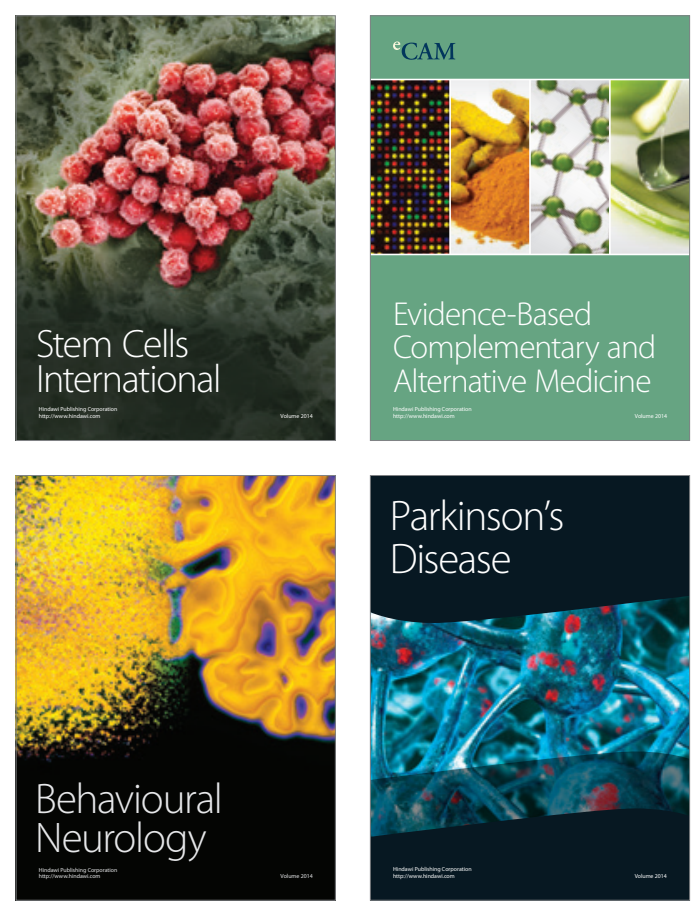

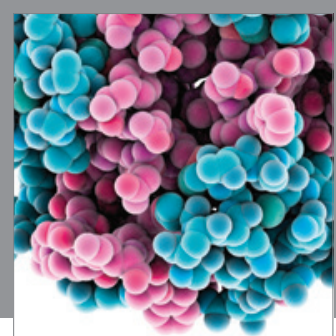

Journal of
Diabetes Research

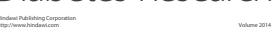

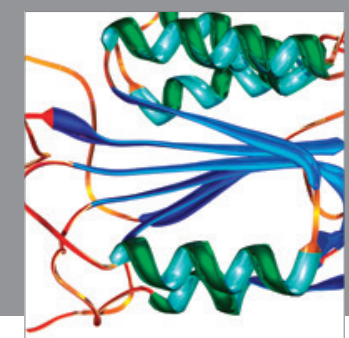

Disease Markers
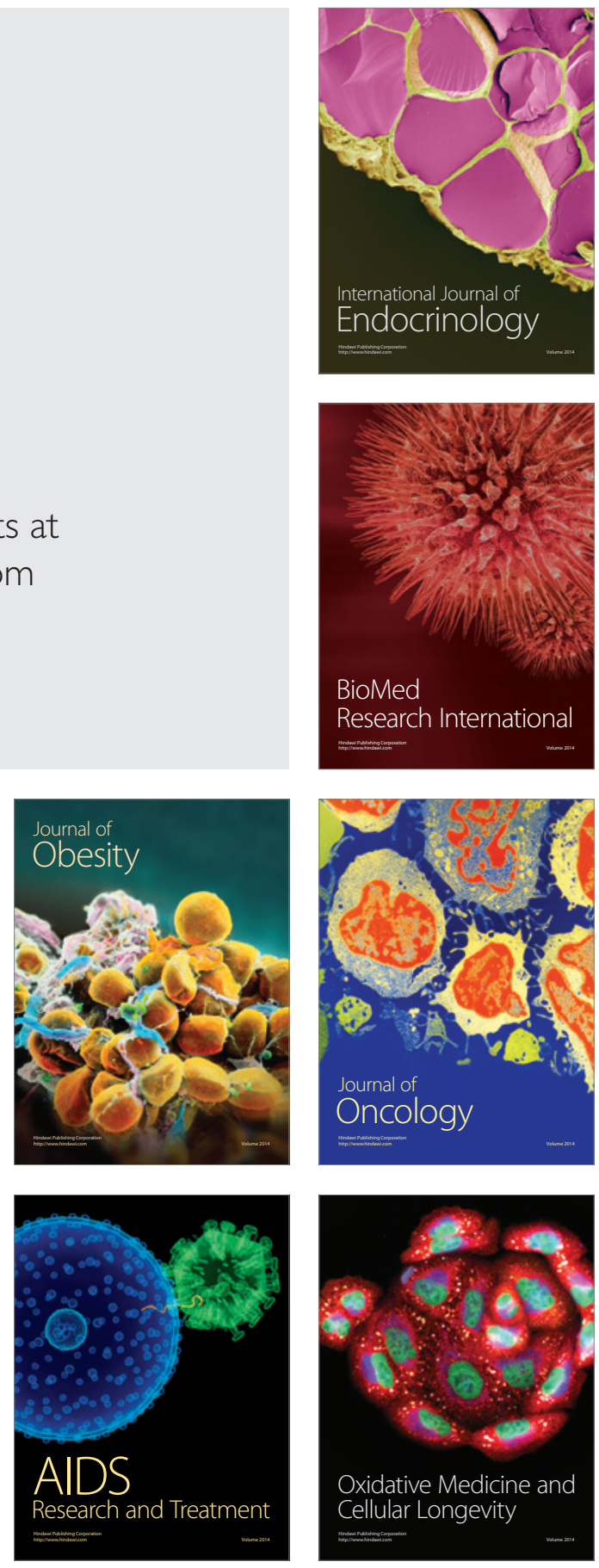